\title{
Effectivity of Thromboprophylxie in Dakar's Medical Areas
}

\author{
B. Djiba1, M. Dieng1, C. M. A. Halim¹, M. Sow ${ }^{1}$, B. S. Kane, M. A. Ndour'1, B. C. Fall2, N. Diagne1, \\ A. C. Ndao' ${ }^{1}$, A. Faye ${ }^{1}$, S. Ndongo ${ }^{2}$, A. Pouye ${ }^{1}$ \\ ${ }^{1}$ Department of Internal Medicine, Aristide Le Dantec Hospital, Dakar-Étoile, Senegal \\ ${ }^{2}$ Department of Internal Medicine, Dalal Jam Hospital, Dakar, Senegal \\ Email: boundiadjiba@yahoo.fr
}

How to cite this paper: Djiba, B., Dieng, M., Halim, C.M.A., Sow, M., Kane, B.S., Ndour, M.A., Fall, B.C., Diagne, N., Ndao, A.C., Faye, A., Ndongo, S. and Pouye, A. (2020) Effectivity of Thromboprophylxie in Dakar's Medical Areas. Open Journal of Internal Medicine, 10, 35-43.

https://doi.org/10.4236/ojim.2020.101004

Received: December 7, 2019

Accepted: February 22, 2020

Published: February 25, 2020

Copyright $\odot 2020$ by author(s) and Scientific Research Publishing Inc. This work is licensed under the Creative Commons Attribution International License (CC BY 4.0).

http://creativecommons.org/licenses/by/4.0/

(c) (i) Open Access

\begin{abstract}
Introduction: Venous thromboembolic disease (VTE) is a real public health problem worldwide. The practice guide produced periodically by the American College of Chest Physicians (ACCP) has become the international standard. However, thromboprophylaxis remains underused. Methodology: We carried out a descriptive cross-sectional study. The goals of that study were to evaluate the effectiveness of the practice of thromboprophylaxis in the various medical services of the Dakar Public Hospitals. Our investigation was conducted for two weeks in September 2017. Results: 160 patients were included (81 men and 79 women) in our series, with male predominance: sex ratio of 1.02. The average age was 48 . Infectious pathologies were the predominant clinical pictures (35\% of cases). The thromboembolic risk factors (RF) mainly found were represented by prolonged bed rest, followed by cardiovascular (RF): age greater than 60 years (31.2\%), hypertension (8.8\%), obesity $(4.4 \%)$ and diabetes (3.8\%). The thromboembolic RF of patients hospitalized in these medical services has been evaluated empirically. We noted a lack of use of the VTE risk assessment scores. $40.9 \%(n=56)$ of patients received overall VTE prophylaxis, a rate corresponding to almost half of those at risk (51.4\%). This result reflects an under-use of thromboprophylaxis in the Dakar medical environment and a low level of adherence by practicians to the guidelines on VTE prophylaxis. Conclusion: It is therefore recommended to develop a national strategy to assess patients at risk for VTE, as well as measures to educate and inform doctors about the appropriate forms of thromboprophylaxis.
\end{abstract}

\section{Keywords}

Thromboprophylaxis, Anticoagulant, Thromboembolic Disease 


\section{Introduction}

The concept of venous thromboembolic disease (VTE) brings together two progressive entities: deep vein thrombosis (DVT) and pulmonary embolism (PE). It is a major public health issue, it represents the fourth leading cause of death in industrialized countries, the third leading cause of cardiovascular death behind myocardial infarction (MI) and strokes [1] [2] [3] and the leading cause of preventable hospital mortality [4]. The incidence of VTE is often underestimated because it can be asymptomatic, misdiagnosed or not reported as the root cause of death.

In France, it is estimated respectively for DVT and PE of 1.24/1000/year and $0.6 / 1000 /$ year and associated mortality in $5 \%$ to $10 \%$ of cases [5]. In Heit's study, the overall mortality of patients with VTE was $25 \%$ at seven days, $30 \%$ at three months, and $40 \%$ at two years [6].

VTE is an absolute medical emergency. Hence the major interest of its prevention. The set of pharmacological and or mechanical means intended to prevent the appearance of a thrombus defines thromboprophylaxis.

This makes it possible to halve the risk of a thromboembolic event during hospitalization in medicine [7]. While the prevention of VTE is widely observed in surgical patients, this practice is less widespread in patients hospitalized in medicine [8]. The heterogeneity of situations and risk factors presented by patients in the medical environment makes recommendations more difficult to establish [9].

The importance of thromboprophylaxis in patients hospitalized for an acute medical condition, presenting many risk factors (RF) of VTE, is well established. Several essays have proven it: MEDENOX, PREVENT, ARTEMIS [10] [11] [12].

In sub-Saharan Africa, data on risk factors (RF) and prophylaxis are scarce. In Senegal, there are few data on the use of thromboprophylaxis with patients in medical services. However, in a cross-sectional hospital survey dating from 2011, Bâ et al. [13] reported a low rate of thromboprophylaxis in Senegalese hospitals. The prophylaxis proportion was $33.8 \%$ (46/136) in medicine and $37.5 \%$ (48/128) in surgery.

In our context, due to the scarcity of data and in order to draw a portrait of the current local situation, we wanted to evaluate the practice of drug thromboprophylaxis in a medical environment in Dakar. So, we conducted a study whose objectives were to assess.

- The thromboembolic risk in patients hospitalized in a Dakar medical environment;

- The use of risk scores and their practice in hospitalized patients;

- The prevalence of thromboprophylaxis in hospitalized patients and the correlation with the risk scores used.

\section{Patients and Methods}

We had conducted a descriptive cross-sectional study during the first two weeks 
of September at the departments of Medicine of Fann's public health establishments (Pulmonology, Neurology, Infectious diseases) and Le Dantec (Internal medicine, Cardiology, Nephrology, Dermatology). It concerned all patients hospitalized in these departments during that period, whether or not they received a drug thromboprophylaxis. Hospitalized patients outside of this period were not included. Those who were on curative anticoagulation were excluded. The assessment was made over one day after agreement with the heads of the departments concerned. Data collection and collection was carried out using a pre-established questionnaire. We carried out a study of the records of all hospitalized patients, looking for criteria that could justify thromboprophylaxis. We also looked into the case where the patient was anticoagulated, the use of scores or recommendations that justified the thromboprophylaxis. The analysis and the exploitation of the data were made from a data collection sheet and the ethical considerations were respected.

\section{Results}

One hundred and sixty patients (160) were included: eighty-two (82) at the Fann Public Hospital. The investigation concerned four services at Le Dantec and three services at Fann. The majority of patients were identified in the departments of pneumology, cardiology and infectious diseases with respectively $21.9 \%, 18.1 \%$ and $15.6 \%$ (Table 1). Our population consisted of 81 men (50.6\%) and 79 women $(49.4 \%)$, a sex ratio of 1.02 . The average age was 47.95 years with extremes ranging from 10 years (a few pediatric patients found in the Department of Infectious Diseases and Fann Neurology) to 90 years old. The majority of our patients were between 20 and 40 years old, in $31.9 \%$ of cases $(n=51)$ and between 40 and 60 years old, or $30.6 \%$ of cases $(n=49)$. Over 60 years in $31.2 \%$ of cases $(n=50)$ (Figure 1 ).

Regarding the history of our patients, prolonged bed rest was the most common with $75.6 \%$ of cases. Two patients had a history of venous thrombosis (Table 2). Infectious disease was the main reason for hospitalization of our patients, in $35 \%$ of cases; followed by the other unrecognized diagnoses of our questionnaire items, then heart failure and ischemic stroke with $10.6 \%$ and $8.1 \%$ of cases, respectively. The thromboembolic risk assessment using a score was only performed in four patients, three with the revised Geneva score and one with the Wells score. No Padua score was used. Almost all of the anticoagulated patients were on Low molecular weight héparine (LMWH), i.e. in $77.2 \%$ of cases $(\mathrm{n}=61)$. The Anti-Vitamin K (AVK) was prescribed in eight patients and the combination LMWH and AVK in eight patients is $10.12 \%$. Among the anticoagulated patients $(\mathrm{N}=79)$, the majority had benefited from a preventive dose, in $70.8 \%$ of the cases $(n=56)$ and 23 patients $(29.2 \%)$ from a curative dose. Thromboprophylaxis was more practiced in pulmonology (28.6\%) and neurology. The twenty-three patients $(n=23)$ who received curative dose anticoagulation therapy were excluded from the study. 
Table 1. Percentage of patients by service.

\begin{tabular}{cccc}
\hline & Number & Percentage validated & Cumulated Percentage \\
\hline Cardiology & 29 & 18.1 & 18.1 \\
Néphrology & 13 & 8.1 & 26.3 \\
Dermatology & 17 & 10.6 & 36.9 \\
Internal medicine & 19 & 11.9 & 48.8 \\
Neurology & 22 & 13.8 & 62.5 \\
Infectious deseases & 25 & 15.6 & 78.1 \\
Pneumology & 35 & 21.9 & 100 \\
Total & 160 & 100 & 100 \\
\hline
\end{tabular}

Table 2. Distribution of patients according to their antecedents.

\begin{tabular}{ccc}
\hline Antecedents & Number & Percentage \\
\hline Diabetes & 6 & 3.8 \\
High blood pressure & 14 & 8.8 \\
auto-immune and auto-inflammatory disease & 3 & 1.9 \\
Neoplasia & 3 & 1.9 \\
Prolonged alitation & 121 & 75.6 \\
Antecedents of veinous thrombosis & 2 & 1.2 \\
Hormone therapy & 0 & 0 \\
No antecedents & 11 & 6.8 \\
Total & 149 & 93.3 \\
\hline
\end{tabular}

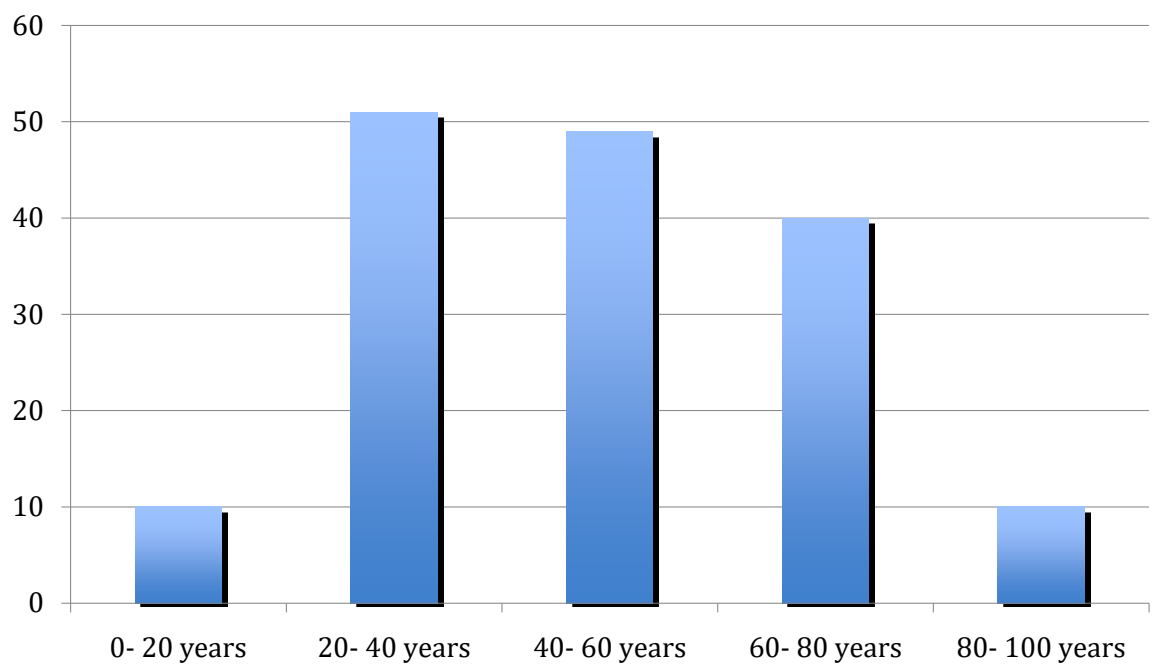

Figure 1. Number of patients by age in years.

Of the remaining one hundred and thirty-seven, in general; $40.9 \%$ of patients had received VTE prophylaxis $(n=56)$ and $59.1 \%$ of patients had not received it $(\mathrm{n}=81)$. One hundred and nine patients $(\mathrm{n}=109)$ had a theoretical indication 
for thromboprophylaxis, patients who had venous thromboembolic RF. This general thromboprophylaxis rate (at 40.9\%) corresponds to almost half of the subjects with a theoretical indication for VTE prophylaxis (51.4\% of patients at risk). We did not find an excess of thromboprophylaxis. Preventive dose anticoagulation patients all had VTE risks. In patients at risk for VTE, having this theoretical indication for thromboprophylaxis; $48.6 \%$ had not received venous thromboembolic prophylaxis $(n=53)$ as shown in Table 3 and Table 4.

\section{Discussion}

The male predominance of our study population (a sex ratio of 1.02) is found in the series of Bâ [13] and Gueye Dia [2] who had a sex ratio of 1.21. The age of our study population was relatively young with an average age of 48 years superimposable on that found by Gueye Dia [2] and different from that of studies, Bâ [13], Ambarish Pandey [14] and N. Maggy Bertran [9] who were respectively 62 years, 43.7 years and 66.4 years. This difference in age is due to the fact that these studies exclusively included patients whose age exceeded 40 years [13], in the same way, the aging of the Western population can be an explanation for this discrepancy.

Infectious pathology remains the predominant pathology in our series (35\% of cases). This predominance is due to the tropical context in which we operate. These data confirm Magy-Bertrand's work on the evaluation of thromboprophylaxis in an internal medicine department in 2010 (CHU Besançon in France) in which the infectious pathology predominated $33.7 \%$ of the reasons for hospitalization). But also those of Ba et al. [13] in the ENDORSE study on the evaluation of the prevalence of VTE risk and thromboprophylactic coverage in the

Table 3. Distribution of patients with and without risk factors.

\begin{tabular}{ccccc}
\hline & \multicolumn{2}{c}{ Number } & Total & Percentage \\
\hline & $\begin{array}{c}\text { Patients with risk } \\
\text { factors }\end{array}$ & $\begin{array}{c}\text { Patients without risk } \\
\text { factors }\end{array}$ & & \\
$\begin{array}{c}\text { Preventive } \\
\text { anticoagulation dose }\end{array}$ & 56 & 0 & 56 & 40.9 \\
Not anticoagulated & 53 & 28 & 81 & 59.1 \\
Total & 109 & 28 & 137 & 100 \\
\hline
\end{tabular}

Table 4. Percentage of anticoagulated patients or not with venous thromboembolic risk factors.

\begin{tabular}{ccc}
\hline & \multicolumn{2}{c}{ Patient with risk factors of venous thrombosis } \\
\hline Preventive anticoagulation & Number & Percentage \\
Without preventive anticoagulation & 56 & 51.4 \\
Total & 53 & 48.6 \\
& 109 & 100 \\
\hline
\end{tabular}


context of acute care at the national level in the country (Senegal) in 2011, work has highlighted a predominance of infectious pathology. In this work, respiratory and non-respiratory infectious diseases represented $20 \%$ of the cases of patients who presented a thromboembolic risk. In our series, autoimmune pathology was found in $1.9 \%$ of the cases $(n=3)$. This small proportion of autoimmune pathology can be explained by the rarity of hospitalizations for autoimmune disease in the various hospital departments outside the internal medicine and dermatology departments of Le Dantec Hospital.

The thromboembolic RF that we found in this study was represented by prolonged bed rest $(75.6 \%)$ linked to the severity of the pathologies found which requires hospitalization of patients despite their relatively young age. Like other RF, we can note the age over 60 years (31.2\%), hypertension (8.8\%), obesity $(4.4 \%)$ and diabetes $(3.8 \%)$ and less frequently neoplasias and autoimmune diseases. Our results are comparable to those of Endorse in Tunisia [15], where the risk factors were dominated by cardiovascular pathologies (40\%) followed by pulmonary infections (36.1\%). Poittier [16] found a preponderance of stasis factors in his series with age over 60 (70\%), heart failure (17\%), active cancer (8\%). Ba et al. [13] in Senegal in their Endorse series, had RF dominated, in order, by cardiovascular pathologies, pulmonary infections, other infectious diseases and neurological diseases.

Only $40.9 \%$ of our patients $(n=56)$ received VTE prophylaxis. This overall thromboprophylaxis rate corresponds to almost half of the subjects at risk (51.4\% of patients with a theoretical indication for TE prophylaxis). Our results are higher than those of $\mathrm{Ba}$ et al. [13], who estimated the proportion of thromboprophylaxis in medicine at $33.8 \%$, thus reporting thromboprophylaxis coverage from $0 \%$ to $50 \%$ in medical services in Senegal in 2011. According to them, less than a third of patients at risk for thromboembolism benefited from prevention. Despite this low prevalence of thromboprophylaxis (40.9\%) of our results, we found that this prevalence is largely above that noted by Gueye Dia [2] who had evaluated thromboprophylaxis in the internal medicine department of Le Dantec at $12 \%$ in 2015, and that of the Dédonougbo series [17] at the Cotonou university hospital in 2009 with a prevalence of $6 \%$. Our results also confirm the overall trend of increasing proportions of patients on thromboprophylaxis. In fact, despite this underuse of prophylaxis, there is an improvement compared to the prevalence figures from previous studies at the national level [2] [13] and compared to a study carried out in another country in the process of development like India.

The Endorse Bergmann study concluded that prophylaxis recommended by ACCP was underutilized worldwide, in the medical patient population, and was provided to less than $40 \%$ of patients at risk. [18] is justified by an underuse of VTE prophylaxis in medical services which may reflect a low level of perception of the risk of VTE among certain hospital doctors, combined with a lack of awareness of the benefits of VTE prophylaxis according to Bergmann JF [18]. Despite the low prevalence of VTE prophylaxis in our results (40.9\%), the latter 
confirms this overall trend of increasing proportions of patients on thromboprophylaxis. Even if it is suboptimal, it is higher than those observed by Bergman et al. who estimated VTE prophylaxis to less than $40 \%$ of patients hospitalized in medical services in 2010. This could perhaps be explained by taking awareness by hospital doctors of VTE risks. Overall, in 2008, the highest prevention rates were obtained in the countries of the North. It was $51.8 \%$ in Western Europe and the USA with a world average of $48 \%$ [19]. The contrast between the improvement in rates of VTE prophylaxis and the absence of use of risk scores in our study could result from poor adherence to the guidelines for good VTE prophylaxis in our context unlike developed countries.

According to Alhajri et al. [20] in a prospective observational study of medical patients in a tertiary care hospital in the United Arab Emirates in 2015 and relating to adherence to the ACCP 2012 guidelines in thromboembolic prophylaxis, certain recommendations could allow to perform effectively VTE prophylaxis. These were: the good observance of these guidelines, the dosage and indication of prophylaxis, and finally the evaluation of the VTE risk with the use of Padua scores (predictive score of VTE for the establishment anti-thrombotic prophylaxis) as well as the risk of bleeding or hemorrhagic risks with the IMPROVE Score. In our study, we find that the absence of hemorrhagic risk assessment or the non-use of risk scores are factors that could explain this deficit in terms of prophylaxis of MVTE.

Therapeutically, low molecular weight heparins were mainly used $85.7 \%$ (Enoxaparin) in the thromboprophylaxis of our series. This is consistent with the result of $\mathrm{Ba}$ et al. for which Enoxaparin was the most widely represented prescription in TVE prophylaxis. The limits of our study were: some doctors felt evaluated which limited pau their participation, the limited financial means in some who were the cause of their non anticoagulation, the absence of follow-up of the fate of his non anticoagulated patients despite scores high risk

\section{Conclusion}

VTE is a major clinical concern with a significant risk of morbidity and mortality in hospitalized patients. Its prevention should not be overlooked. Analysis of the practices of this thromboprophylaxis has shown great heterogeneity in these medical services. $40.9 \%$ of patients $(n=56)$ received VTE prophylaxis. This overall thromboprophylaxis rate corresponds to almost half of the subjects at risk, i.e. $51.4 \%$ of patients with a theoretical indication for thromboprophylaxis. Despite the overall trend of increasing proportions of patients on thromboprophylaxis with a prevalence higher than that of the data collected from previous studies; our results clearly demonstrate this underuse of VTE prophylaxis. Various factors have played an important role in the ineffectiveness and lack of safety during VTE prophylaxis. These factors include: poor adherence to VTE guidelines, inappropriate dosing and monitoring of thromboprophylaxis and lack of VTE risk assessment tools. However even if these VTE risk assessment tools 
such as the Padua score are available in the health information system, their ignorance or reluctance to use them and/or poor documentation is not uncommon. The prevention of VTE must be an integral part of the therapeutic panoply to reduce morbidity and mortality and provide the patient with a better quality of life, especially in hospitals. It is therefore recommended: to develop a national strategy to assess patients at risk for VTE, as well as measures to educate and inform doctors about the appropriate forms of thromboprophylaxis.

\section{Conflicts of Interest}

The authors declare no conflicts of interest regarding the publication of this paper.

\section{References}

[1] Abildstrom, S.Z., Rasmussen, S., Rosén, M., et al. (2003) Trends in Incidence and Case Fatality Rates of Acute Myocardial Infarction in Denmark and Sweden. Heart, 89, 507-511. https://doi.org/10.1136/heart.89.5.507

[2] Dia, D.G., Fall, S., Dia, A.D., et al. (2015) Evaluation du risque thromboembolique veineux et pratique de la thromboprophylaxie en médecine interne. Pan African Medical Journal, 22, 386. https://doi.org/10.11604/pamj.2015.22.386.7988

[3] Anderson, F.A., Wheeler, H.B., Goldberg, R.J., et al. (1991) A Population-Based Perspective of the Hospital Incidence and Case-Fatality Rates of Deep Vein Thrombosis and Pulmonary Embolism. Archives of Internal Medicine, 151, 933-938. https://doi.org/10.1001/archinte.1991.00400050081016

[4] Geerts, W.H., Pineo, G.F., Heit, J.A., et al. (2004) Prevention of Venous Thromboembolism: The Seventh ACCP Conference on Antithrombotic and Thrombolytic Therapy. Chest, 126, 338S-400S. https://doi.org/10.1378/chest.126.3_suppl.338S

[5] Oger, E., et al. (2000) Incidence of Venous Thromboembolism: A Community-Based Study in Western France. EPI-GETBP Study Group. Groupe d'Etude de la Thrombose de Bretagne Occidentale. Thrombosis and Haemostasis, 83, 657-660. https://doi.org/10.1055/s-0037-1613887

[6] Heit, J.A., Silverstein, M.D., Mohr, D.N., et al. (2001) The Epidemiology of Venous Thromboembolism in the Community. Thrombosis and Haemostasis, 86, 452-463. https://doi.org/10.1055/s-0037-1616243

[7] Bertoletti, L., Lega, J.C., Accassat, S., et al. (2013) Thromboprophylaxie en médecine: quelles modifications avec les nouveaux anticoagulants oraux? La Presse Médicale, 42, 1219-1224. https://doi.org/10.1016/j.lpm.2013.06.002

[8] Tapson, V.F., Decousus, H., Pini, M., et al. (2007) Venous Thromboembolism Prophylaxis in Acutely Ill Hospitalized Medical Patients: Findings from the International Medical Prevention Registry on Venous Thromboembolism. Chest, 132, 936-945. https://doi.org/10.1378/chest.06-2993

[9] Magy-Bertrand, N., Auzas, O., Meaux-Ruault, N., et al. (2010) Évaluation de la thromboprophylaxie dans un service de médecine interne. La Revue de Médecine Interne, 6, 406-410. https://doi.org/10.1016/j.revmed.2010.01.004

[10] Cohen, A.T., Davidson, B.L., Gallus, A.S., et al. (2006) Efficacy and Safety of Fondaparinux for the Prevention of Venous Thromboembolism in Older Acute Medical Patients: Randomised Placebo Controlled Trial. BMJ, 332, 325-329. https://doi.org/10.1136/bmj.38733.466748.7C 
[11] Leizorovicz, A., Cohen, A.T., Turpie, A.G., et al. (2004) Randomized, Placebo Controlled Trial of Dalteparin for the Prevention of Venous Thromboembolism in Acutely Ill Medical Patients. Circulation, 110, 874-879. https://doi.org/10.1161/01.CIR.0000138928.83266.24

[12] Samama, M.M., Cohen, A.T., Darmon, J.Y., et al. (1999) A Comparison of Enoxaparin with Placebo for the Prevention of Venous Thromboembolism in Acutely Ill Medical Patients. Prophylaxis in Medical Patients with Enoxaparin Study Group. The New England Journal of Medicine, 341, 793-800. https://doi.org/10.1056/NEJM199909093411103

[13] Bâ, S.A., Badiane, S.B., Diop, S.N., et al. (2011) A Cross-Sectional Evaluation of Venous Thromboembolism Risk and Use of Venous Thromboembolism Prophylaxis in Hospitalized Patients in Senegal. Archives of Cardiovascular Diseases, 104, 493-501. https://doi.org/10.1016/j.acvd.2011.05.007

[14] Pandey, A., Patni, N., Singh, M., et al. (2009) Assessment of Risk and Prophylaxis for Deep Vein Thrombosis and Pulmonary Embolism in Medically Ill Patients during Their Early Days of Hospital Stay at a Tertiary Care Center In a Developing Country. Vascular Health and Risk Management, 5, 643-648. https://doi.org/10.2147/VHRM.S6416

[15] Jerbi, Z., Houman, M.H., Ghedira, H., et al. (2011) Venous Thromboembolism Risk and Prophylaxis in the Acute Hospital Care Setting-Results of the ENDORSE Study in Tunisia. La Tunisie Médicale, 89, 784-89.

[16] Pottier, P., Planchon, B., Pistorius, M.A., et al. (2002) Facteurs de risque de la maladie thromboembolique veineuse chez des malades hospitalisés en médecine interne: une enquête cas-témoins sur 150 patients. La Revue de Médecine Interne, 23, 910-918. https://doi.org/10.1016/S0248-8663(02)00686-0

[17] Martin Houénassi, D., Tchabi, Y., Akindès-Dossou Yovo, R., et al. (2009) Prevention of Venous Thromboembolism among Inpatients at Cotonou Teaching Hospital, Benin. Archives of Cardiovascular Diseases, 102, 5-9. https://doi.org/10.1016/j.acvd.2008.10.009

[18] Bergmann, J.F., Cohen, A.T., Tapson, V.F., et al. (2010) Venous Thromboembolism Risk and Prophylaxis in Hospitalised Medically Ill Patients. The ENDORSE Global Survey. Thrombosis and Haemostasis, 103, 736-748. https://doi.org/10.1160/TH09-09-0667

[19] Bergmann, J.F., Cohen, A.T., Tapson, V.F., et al. (2008) Risque de maladie thromboembolique veineuse et pratique de préventions hospitalières en médecine interne: Résultas obtenus en France de l'étude internationale ENDORSE. La Revue de Médecine Interne, 29, 397. https://doi.org/10.1016/j.revmed.2008.10.293

[20] AlHajri, L. and Gebran, N. (2015) The Use of Low Molecular Weight Heparin for Venous Thromboembolism Prophylaxis in Medical Patients: How Much Are We Adherent to the Guidelines? Open Journal of Internal Medicine, 5, 81-91. https://doi.org/10.4236/ojim.2015.54012 